\title{
Identification of the Optimum Locations of Power System Stabilizers in a Multimachine Power System Using Second Order Eigenvalue Sensitivity Analysis
}

\author{
Abdul Mahabuba ${ }^{1}$, Abdullah Khan ${ }^{2}$ \\ ${ }^{1}$ College of Engineering and Applied Sciences, Al Ghurair University, Dubai, UAE; ${ }^{2}$ Department of Electrical and Electronics Engi- \\ neering, B.S. Abdur Rahman University of Science and Technology, Chennai, India. \\ Email:mifarz@yahoo.com
}

Received April $8^{\text {th }}, 2012$; revised November $8^{\text {th }}, 2012$; accepted November $15^{\text {th }}, 2012$

\begin{abstract}
This research paper deals with the identification of the best location of the Power System Stabilizers (PSS) and also the tuning of PSS parameters in order to improve the overall dynamic stability of multi machine power systems. The location of PSS is determined by identifying the critical modes and their corresponding first and second order eigenvalue sensitivities. In this formulation, sensitivity analysis of a particular mode can be performed with only its eigenvalues and their left and right eigenvectors. The simplicity and efficiency of this approach sharply contrast to the complexity of the traditional approach, where all eigenvalues and eigenvectors are required at the same time. The effectiveness of this method in selecting the optimum location for placement of PSSs is compared with the participation factor method. The proposed sensitivity theory used to identify the best PSS location in a five machine, eight bus El-Metwally and Malik System to increase the damping of both local and inter area modes for various operating conditions.
\end{abstract}

Keywords: Power System Stabilizer (PSS); Small Signal Stability; First Order Eigenvalue Sensitivity (FOES); Second Order Eigenvalue Sensitivity (SOES); Participation Factor (PF)

\section{Introduction}

Power systems are highly complex systems that contain non-linear and time varying elements. Many power systems face the problem of troublesome dynamic oscillations in the range of 0.2 to $2.5 \mathrm{~Hz}$ associated with some poorly damped swing modes. Power system stabilizers (PSSs) are commonly used to damp these oscillations and increase damping of swing modes [1]. In the application of PSS to increase the damping of a certain troublesome mode in a multi machine power system the very first step is to determine the best PSS location(s). For a local mode the job of selecting PSS location(s) is not difficult because only few machines are involved in this local oscillation and there are only a few choices. But for the inter area mode large number of machines may be involved in the oscillation. This makes the PSS location selecting problem very complicated [2]. The most commonly used approach for stability siting was the Eigen vector method proposed by DeMello et al. [3]. This method too may fail in certain circumstances and may lead to undesirable stabilizer location as found out in various studies. Hiyama [4] presented an approach using the concept of coherent groups. This method suffers from the major disadvantage that generators within one coherent group for a large disturbance do not necessarily remain in the same group under small-disturbance conditions.

Zhang and Coonick [5] proposed a new method based on the method of inequalities for the coordinated synthesis of PSSs parameters in multi-machine power system in order to enhance overall system small signal stability. Antonio et al. [6] presented a method that simultaneously tune multiple power system damping controllers using Genetic Algorithms. Cai and Elrich [7] suggested the simultaneous coordinated tuning of the series FACTS Power Oscillation Damping controller in multi-machine power system. Doi and Abe [8] developed a new coordinated synthesis method by combining eigenvalue sensitivity analysis and linear programming applied to this method is used to synthesize the coordination of power system stabilizers in a new multi machine system.

In this paper, the first order and second order eigenvalue sensitivity theory presented in [9-12] used for selection of optimum locations of PSS and the same is compared with the participation factor method. This method is used to identify the best PSS locations in a five-machine, eight bus system (El-Metwally and Malik 
System) to increase the damping of an inter area mode for three different operating conditions. The dynamic response of rotor angle deviation of the system confirms that the prediction of the best PSS location by the proposed method is correct and accurate. Section 2 discusses about first order and second order eigenvalue sensitivity analysis. Section 3 presents the dynamic stability model of multimachine power systems. Section 4 discusses the proposed method of optimum locations of PSSs. Section 5 provides the simulation results and Section 6 gives the conclusion.

\section{Eigenvalue Sensitivity}

The linearized model is as shown in Equation (1)

$$
\dot{x}=[A] x
$$

The eigenvalues of a matrix $A$ are given by non-trivial solutions to the equation :

$$
(A-\lambda I) \Phi=0
$$

where $\mathrm{A}$ is an $\mathrm{n} \times \mathrm{n}$ matrix and $\Phi$ is a $\mathrm{nx} 1$ vector.

For any eigenvalue $\lambda_{i}$, the $\mathrm{n}$ column vector $\varphi_{i}$, which satisfies Equation (2), is called the right eigenvector of $A$ associated with the eigenvalue $\lambda_{i}$.

Therefore we have,

$$
A \varphi_{i}=\lambda_{i} \varphi_{i}
$$

Similarly, the n-row vector $\psi_{i}$ which satisfies

$$
\psi_{i} A=\lambda_{i} \psi_{i}
$$

which is called the left eigenvector associated with the eigenvector $\lambda_{i}$.

Consider the equation,

$$
[A]\left[\varphi_{i}\right]=\lambda_{i}\left[\varphi_{i}\right]
$$

Sensitivityof eigenvalues with respect to elements of [A],

$$
\frac{\partial[A]}{\partial a k j}\left[\varphi_{i}\right]+[A] \frac{\partial\left[\varphi_{i}\right]}{\partial a k j}=\frac{\partial \lambda_{i}}{\partial a k j}\left[\varphi_{i}\right]+\lambda_{i} \frac{\partial\left[\varphi_{i}\right]}{\partial a k j}
$$

Premultiplying the Equation (6) by $\left[\psi_{i}\right] \&$ noting that $\left[\psi_{i}\right]\left[\varphi_{i}\right]=1 \quad \&\left[\psi_{i}\right]\left([A]-\lambda_{i}[I]\right)=0$ results,

$$
\left[\psi_{i}\right] \frac{\partial[A]}{\partial a k j}\left[\varphi_{i}\right]=\frac{\partial \lambda_{i}}{\partial a k j}
$$

All elements of $\frac{\partial A}{\partial a_{k j}}=[0]$ for all $k \neq j$ and 1 for $k=j$

$$
\frac{\partial \lambda_{i}}{\partial a k j}=\Psi i k \Phi j i(i, k, j=1,2, \cdots, n)
$$

Differentiate Equation (7) with respect to PSS pa- rameter $K_{\mathrm{pss}}$ gives Equation (8):

$$
\frac{\partial A}{\partial K_{\mathrm{pss}}} \varphi_{i}+A \frac{\partial \varphi_{i}}{\partial K_{\mathrm{pss}}}=\frac{\partial \lambda_{i}}{\partial K_{\mathrm{pss}}} \varphi_{i}+\lambda_{i} \frac{\partial \varphi_{i}}{\partial K_{\mathrm{pss}}}
$$

Differentiating Equation (8) with respect to another PSS parameter $T_{1}$, then simplify yield the second order eigenvalue sensitivity $[14,15]$ as below:

$$
\begin{aligned}
\frac{\partial^{2} \lambda_{i}}{\partial T_{1} \partial K_{\mathrm{pss}}}= & \frac{1}{\psi_{i} \varphi_{i}}\left(\psi_{i} \frac{\partial^{2} A}{\partial T_{1} \partial K_{\mathrm{pss}}} \varphi_{i}+\psi_{i} \frac{\partial A}{\partial K_{\mathrm{pss}}} \sum_{\substack{j=1 \\
j \neq i}}^{n} \beta_{i j} \varphi_{j}\right. \\
& \left.+\psi_{i} \frac{\partial A}{\partial T_{1}} \sum_{\substack{j=1 \\
j \neq i}}^{n} \alpha_{i j} \varphi_{j}\right)
\end{aligned}
$$

where

$$
\begin{gathered}
\alpha_{i j}=\frac{\psi_{j} \frac{\partial A}{\partial K_{\mathrm{pss}}} \varphi_{i}}{\psi_{j} \varphi_{j}\left(\lambda_{i}-\lambda_{j}\right)} \\
\beta_{i j}=\frac{\psi_{j} \frac{\partial A}{\partial T_{1}} \varphi_{i}}{\psi_{j} \varphi_{j}\left(\lambda_{i}-\lambda_{j}\right)}
\end{gathered}
$$

The Equation (9) requires knowledge of all eigenvalues and eigenvectors, which is very large problem to solve when the system matrix is very large. To find the second order eigenvalue sensitivities without having to know all the eigenvalues and eigenvectors, the second order eigenvalue sensitivities can be written in terms of two first order eigenvector sensitivities [4] as Equation (10):

$$
\begin{aligned}
\frac{\partial^{2} \lambda_{i}}{\partial T_{1} \partial K_{\mathrm{pss}}}= & \frac{1}{\psi_{i} \varphi_{i}}\left(\psi_{i} \frac{\partial^{2} A}{\partial T_{1} \partial K_{\mathrm{pss}}} \varphi_{i}+\psi_{i}\left[\frac{\partial A}{\partial K_{\mathrm{pss}}}\right.\right. \\
& \left.\left.-\frac{\partial \lambda_{i}}{\partial K_{\mathrm{pss}}} I\right] \frac{\partial \varphi_{i}}{\partial T_{1}}+\psi_{i}\left[\frac{\partial A}{\partial T_{1}}-\frac{\partial \lambda_{i}}{\partial T_{1}} I\right] \frac{\partial \varphi_{i}}{\partial K_{\mathrm{pss}}}\right)
\end{aligned}
$$

If the eigenvector sensitivities $\partial \varphi_{i} / \partial K_{\mathrm{pss}}$ and $\partial \varphi_{i} / \partial T_{1}$ are known, then the above equation can easily be computed.

\section{Dynamic Stability Model of Multi Machine Power System}

In stability analysis of a multi-machine system, modeling of all the machines in a more detailed manner is exceedingly complex in view of the large number of synchronous machines to be simulated. Therefore simplifying assumptions are usually made in modeling the system. In this studies two axis model is used for all machines in the test system.

The linearized state equations for the two axis model under the assumption $x_{d}^{\prime}=x_{q}^{\prime}=x^{\prime}$ are given by Ander- 
son [13] as follows:

$$
\begin{aligned}
p \Delta E_{d i}^{\prime}= & \frac{1}{\tau_{q o o^{\prime}}^{\prime}}\left[-\Delta E_{d}^{\prime}-\left(x_{q i}-x_{i}^{\prime}\right) \Delta I_{q}\right] \\
p \Delta E_{q i}^{\prime}= & \frac{1}{\tau_{d o i^{\prime}}^{\prime}}\left[-\Delta E_{F D i}-\Delta E_{q i}^{\prime}+\left(x_{d i}-x_{i}^{\prime}\right) \Delta I_{d i}\right] \\
p \Delta \omega= & \frac{1}{\tau_{j i}}\left[\Delta T_{m i}-\left(\Delta I_{d i} E_{d i o}^{\prime}+\Delta I_{q i} E_{q i o}^{\prime}+I_{q i o} \Delta E_{q i}^{\prime}\right.\right. \\
& \left.\left.+I_{d i o} \Delta E_{d i}^{\prime}\right)-D_{i} \Delta \omega_{i}\right] \\
p \Delta \delta_{i}= & \Delta \omega
\end{aligned}
$$

where the state variables for the machine are

$E_{d}^{\prime}$-direct axis component of voltage behind transient reactance

$E_{q}^{\prime}$-quadrature axis component of voltage behind transient reactance

$\omega$-angular velocity of rotor

$\delta$-rotor angle in radians

The state variables of the machine including the exciter and PSS are given by

$$
X^{T}=\left[E_{q}^{\prime} E_{d}^{\prime} \delta \omega E_{F D} V_{2} V_{s}\right]
$$

A five machine, eight bus El-Metwally and Malik test system (Figure 1) is chosen to investigate the optimum location of the PSS and the tuning of the PSS parameters. The system data is taken from [1].

\section{Proposed Method for the Optimum Location of PSSs}

The step-wise procedure for identifying the best location of PSS as detailed below.

Step 1: Linearize the system at a chosen operating condition and from the linearized system matrix, identify the rotor swing modes including the nature of modes whether local or inter area modes using eigen sensitivity analysis.

Step 2: Determine the critical rotor swing modes which have damping ratio less than a specified value, say

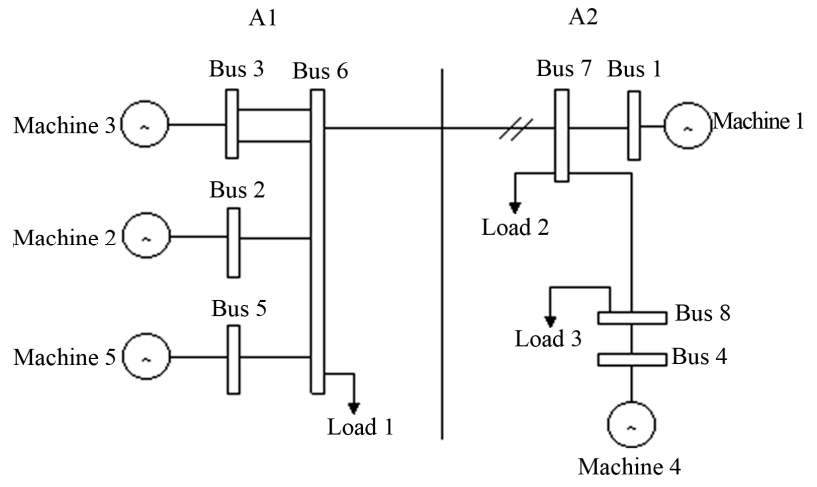

Figure 1. Test system.
0.45 .

Step 3: Steps 1 and 2 are repeated for each chosen operating condition.

Step 4: The critical swing modes of all the operating conditions identified are arranged in the ascending order of the damping ratio. To each critical swing mode associate an operating condition; this has the least damping ratio.

Step 5: The best location for damping the first critical swing mode in the list is obtained using the eigen value sensitivity and participation factors.

Step 6: Step 5 is repeated for all other critical swing modes.

The following three operating conditions are chosen for analysis of the test system:

1) Full load operating condition.

2) Operating condition 1) with load increased by $25 \%$.

3) Full load operating condition with one of the two tie lines between buses 6 and 7 removed.

From Table 1, it is seen that there are four critical swing modes. Mode shapes are obtained by plotting the speed component of the right Eigen vectors of the swing modes as in Figure 2.

From the mode shapes, the first mode is the inter machine oscillation local to area 1 , with $G_{2} \& G_{3}$ swinging

Table 1. Eigenvalues-Operating condition (a).

\begin{tabular}{cc}
\hline Eigenvalues & Damping ratio \\
\hline$-0.0033 \pm \mathrm{j} 0.0537$ & 0.0616 \\
$-0.0009 \pm \mathrm{j} 0.0307$ & 0.0291 \\
$-0.0001 \pm \mathrm{j} 0.0208$ & 0.0068 \\
$-0.0002 \pm \mathrm{j} 0.0084$ & 0.0223 \\
\hline
\end{tabular}

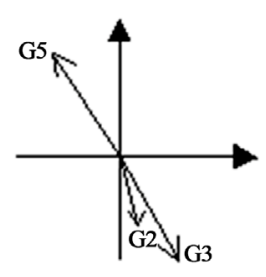

(a) Area 1Local Mode $\lambda=-0.0033 \pm 0.0537 i$

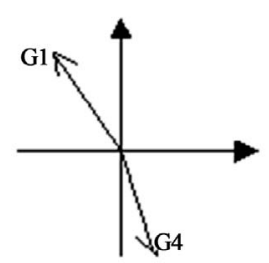

(c) Area 2Local Mode $\lambda=-0.0001 \pm 0.0208 \mathrm{i}$

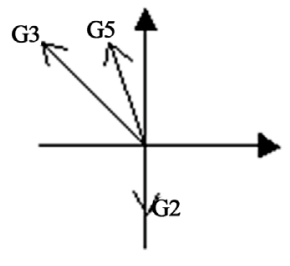

(b) Area 1Local Mode $\lambda=-0.0009 \pm 0.0307 i$
Figure 2. Mode shapes of swing modes. 
against $\mathrm{G}_{5}$. The second mode is the inter machine oscillation local to area 1 , with $G_{2}$ swinging against $G_{3} \& G_{5}$. The third mode is the inter machine oscillation local to area 2 , with $G_{1}$ swinging against $G_{4}$. The fourth mode is an inter-area mode, with generators $\mathrm{G}_{2}, \mathrm{G}_{3}, \mathrm{G}_{5}$ of area 1 swinging against generators $\mathrm{G}_{1}$ and $\mathrm{G}_{4}$ of area 2. The critical modes with their damping ratio, nature of the modes, first order eigen sensitivity value for the three operating conditions are shown in Tables 2-4 respectively.

The critical swing modes identified in all the three operating conditions are arranged in the ascending order of the damping ratio. The operating conditions and related details of the four critical rotor swing modes are given in Table 5.

From Table 5, for the first critical mode, machine 2 is having the highest first order sensitivity (Table 2) and PSS is located at machine 2. Similarly for the second critical mode, machine 2 is having the highest first order sensitivity (Table 2) and PSS is located at machine 2. For the third critical mode, machine 4 is having the highest first order sensitivity (Table 2) and PSS is located at machine 4 . For the fourth critical mode, machine 2 is having the highest first order sensitivity (Table 3 ) and PSS is located at machine 2.

Table 2. Modes and first order eigenvalue sensitivitiesoperating condition (a).

\begin{tabular}{|c|c|c|c|c|}
\hline $\begin{array}{l}\text { Mode } \\
\text { No. }\end{array}$ & Mode & $\begin{array}{l}\text { Damping } \\
\text { ratio }\end{array}$ & $\begin{array}{l}\text { First order } \\
\text { eigenvalue } \\
\text { sensitivity }\end{array}$ & $\begin{array}{l}\text { Nature of the } \\
\text { mode }\end{array}$ \\
\hline \multirow{5}{*}{1} & \multirow{5}{*}{$\begin{array}{c}-0.0033 \pm \\
\mathrm{j} 0.0537\end{array}$} & \multirow{5}{*}{0.0616} & 0.0000 & \multirow{5}{*}{ Local } \\
\hline & & & 0.0091 & \\
\hline & & & 0.0008 & \\
\hline & & & 0.0000 & \\
\hline & & & 0.0013 & \\
\hline \multirow{5}{*}{2} & \multirow{5}{*}{$\begin{array}{c}-0.0009 \pm \\
\mathrm{j} 0.0307\end{array}$} & \multirow{5}{*}{0.0291} & 0.0000 & \multirow{5}{*}{ Local } \\
\hline & & & 0.0111 & \\
\hline & & & 0.0012 & \\
\hline & & & 0.0000 & \\
\hline & & & 0.0002 & \\
\hline \multirow{5}{*}{3} & \multirow{5}{*}{$\begin{array}{c}-0.0001 \pm \\
\mathrm{j} 0.0208\end{array}$} & \multirow{5}{*}{0.0068} & 0.0006 & \multirow{5}{*}{ Local } \\
\hline & & & 0.0020 & \\
\hline & & & 0.0000 & \\
\hline & & & 0.0037 & \\
\hline & & & 0.0000 & \\
\hline \multirow{5}{*}{4} & \multirow{5}{*}{$\begin{array}{c}-0.0002 \pm \\
\mathrm{j} 0.0084\end{array}$} & \multirow{5}{*}{0.0223} & 0.0002 & \multirow{5}{*}{$\begin{array}{l}\text { Inter } \\
\text { area }\end{array}$} \\
\hline & & & 0.0092 & \\
\hline & & & 0.0001 & \\
\hline & & & 0.0012 & \\
\hline & & & 0.0001 & \\
\hline
\end{tabular}

Table 3. Modes and first order eigenvalue sensitivitiesoperating condition (b).

\begin{tabular}{|c|c|c|c|c|}
\hline No & Mode & DR & FOES & Nature \\
\hline \multirow{5}{*}{1} & \multirow{5}{*}{$\begin{array}{c}-0.0079 \pm \\
\mathrm{j} 0.1054\end{array}$} & \multirow{5}{*}{0.0748} & 0.0002 & \multirow{5}{*}{ LOCAI } \\
\hline & & & 0.0004 & \\
\hline & & & 0.0060 & \\
\hline & & & 0.0000 & \\
\hline & & & 0.0000 & \\
\hline \multirow{5}{*}{2} & \multirow{5}{*}{$\begin{array}{c}-0.0020 \pm \\
\mathrm{j} 0.0464\end{array}$} & \multirow{5}{*}{0.0433} & 0.0014 & \multirow{5}{*}{ Local } \\
\hline & & & 0.0038 & \\
\hline & & & 0.0023 & \\
\hline & & & 0.0000 & \\
\hline & & & 0.0000 & \\
\hline \multirow{5}{*}{3} & \multirow{5}{*}{$\begin{array}{c}-0.0001 \pm \\
\mathrm{j} 0.0218\end{array}$} & \multirow{5}{*}{0.0068} & 0.0068 & \multirow{5}{*}{ Local } \\
\hline & & & 0.0015 & \\
\hline & & & 0.0000 & \\
\hline & & & 0.0007 & \\
\hline & & & 0.0000 & \\
\hline \multirow{5}{*}{4} & \multirow{5}{*}{$\begin{array}{c}-0.0003 \pm \\
\mathrm{j} 0.0125\end{array}$} & \multirow{5}{*}{0.0205} & 0.0017 & \multirow{5}{*}{$\begin{array}{c}\text { Inter } \\
\text { area }\end{array}$} \\
\hline & & & 0.0043 & \\
\hline & & & 0.0003 & \\
\hline & & & 0.0004 & \\
\hline & & & 0.0000 & \\
\hline
\end{tabular}

Table 4. Modes and first order eigenvalue sensitivitiesoperating condition (c).

\begin{tabular}{|c|c|c|c|c|}
\hline Mode No. & Mode & $\begin{array}{l}\text { Damping } \\
\text { ratio. }\end{array}$ & $\begin{array}{l}\text { First order } \\
\text { eigenvalue } \\
\text { sensitivity }\end{array}$ & $\begin{array}{l}\text { Nature of the } \\
\text { mode }\end{array}$ \\
\hline \multirow{5}{*}{1} & \multirow{5}{*}{$\begin{array}{c}-0.0080 \pm \\
\mathrm{j} 0.0963\end{array}$} & \multirow{5}{*}{0.0827} & 0.0001 & \multirow{5}{*}{ Local } \\
\hline & & & 0.0005 & \\
\hline & & & 0.0048 & \\
\hline & & & 0.0000 & \\
\hline & & & 0.0002 & \\
\hline \multirow{5}{*}{2} & \multirow{5}{*}{$\begin{array}{c}-0.0019 \pm \\
\mathrm{j} 0.0435\end{array}$} & \multirow{5}{*}{0.0437} & 0.0007 & \multirow{5}{*}{ Local } \\
\hline & & & 0.0050 & \\
\hline & & & 0.0019 & \\
\hline & & & 0.0000 & \\
\hline & & & 0.0001 & \\
\hline \multirow{5}{*}{3} & \multirow{5}{*}{$\begin{array}{c}-0.0001 \pm \\
\mathrm{j} 0.0214\end{array}$} & \multirow{5}{*}{0.0068} & 0.0071 & \multirow{5}{*}{ Local } \\
\hline & & & 0.0008 & \\
\hline & & & 0.0000 & \\
\hline & & & 0.0009 & \\
\hline & & & 0.0000 & \\
\hline \multirow{5}{*}{4} & \multirow{5}{*}{$\begin{array}{c}-0.0003 \pm \\
\mathrm{j} 0.0092\end{array}$} & \multirow{5}{*}{0.0290} & 0.0015 & \multirow{5}{*}{$\begin{array}{l}\text { Inter } \\
\text { area }\end{array}$} \\
\hline & & & 0.0032 & \\
\hline & & & 0.0002 & \\
\hline & & & 0.0002 & \\
\hline & & & 0.0000 & \\
\hline
\end{tabular}


The same procedure outlined in first order is repeated for second order eigenvalue sensitivities to determine the optimum location of PSS. According to second order eigenvalue sensitivity, the results reveal that there are two oscillatory rotor swing modes for each of the three operating conditions which are shown in Tables 6-8 for the operating conditions 1),2) and 3) respectively.

Table 5. Ranking-Critical swing modes (FOES).

\begin{tabular}{ccccccc}
\hline $\begin{array}{c}\text { Rank } \\
\text { order }\end{array}$ & $\begin{array}{c}\text { Critical } \\
\text { mode }\end{array}$ & $\begin{array}{c}\text { Critical } \\
\text { mode }\end{array}$ & $\begin{array}{c}\text { Nature } \\
\text { of mode }\end{array}$ & $\begin{array}{c}\text { Damping Operating Machine } \\
\text { ratio } \\
\text { condition }\end{array}$ & No. \\
\hline 1 & Mode 1 & $\begin{array}{c}-0.0033 \pm \\
0.0537 i\end{array}$ & Local & 0.0616 & (a) & 2 \\
2 & Mode 2 & $\begin{array}{c}-0.0009 \pm \\
0.0307 i\end{array}$ & Local & 0.0291 & (a) & 2 \\
3 & Mode 3 & $\begin{array}{c}-0.0001 \pm \\
0.0208 \mathrm{i}\end{array}$ & Local & 0.0068 & (a) & 4 \\
4 & Mode 4 & $\begin{array}{c}-0.0003 \pm \\
0.0125 i\end{array}$ & $\begin{array}{c}\text { Inter } \\
\text { area }\end{array}$ & 0.0205 & (b) & 2 \\
\hline
\end{tabular}

Table 6. Modes and second order eigenvalue sensitivitiesoperating condition (a).

\begin{tabular}{cccc}
\hline No. & Mode & Damping ratio & $\begin{array}{c}\text { Second order } \\
\text { eigenvalue sensitivity }\end{array}$ \\
\hline & & & 0.0908 \\
1 & $-0.0031 \pm \mathrm{j} 0.0554$ & 0.0559 & $\mathbf{0 . 1 2 9 5}$ \\
& & & 0.0933 \\
& & & 0.0653 \\
& & & 0.0509 \\
& & & 0.0608 \\
& & & 0.3065 \\
& & & \\
& & & 0.2628 \\
& & & 0.1903 \\
& & & 0.1723 \\
\hline
\end{tabular}

Table 7. Modes and second order eigenvalue sensitivitiesoperating condition (b).

\begin{tabular}{cccc}
\hline No. & Mode & $\begin{array}{c}\text { Damping } \\
\text { ratio }\end{array}$ & $\begin{array}{c}\text { Second order } \\
\text { eigenvalue sensitivity }\end{array}$ \\
\hline & & 0.0380 \\
& & & 1.7118 \\
1 & $-0.0031 \pm \mathrm{j} 0.0593$ & 0.0527 & 1.6435 \\
& & & $\mathbf{2 . 4 2 9 4}$ \\
& & & 2.3554 \\
& & & 0.0405 \\
& & & 1.6959 \\
& & & 1.6294 \\
& & & 2.3976 \\
& & & 2.3437 \\
\hline
\end{tabular}

The critical swing modes identified in all the three operating conditions are arranged in the ascending order of the damping ratio. The operating conditions and other related details of the two critical rotor swing modes are given in Table 9.

From Table 9, for the first critical mode, machine 4 is having the highest second order sensitivity (Table 7) and PSS is located at machine 4. Similarly for the second critical mode, machine 2 is having the highest second order sensitivity (Table 6) and PSS is located at machine 2. Hence PSSs are to be located at machines 2 and 4 for two critical rotor swing modes.

The tuning of PSS parameters using Conventional technique has been given below. The gain and time constants of CPSS for the five machines for three operating condition 1), 2), 3) are shown in Table 10.

The effectiveness of the proposed method of location and tuning are investigated by carrying out simulation of the linear model of the system for three operating conditions with disturbances.

Table 8. Modes and second order eigenvalue sensitivitiesoperating condition (c).

\begin{tabular}{|c|c|c|c|}
\hline No. & Mode & Damping ratio & $\begin{array}{c}\text { Second order } \\
\text { eigenvalue sensitivity }\end{array}$ \\
\hline \multirow{5}{*}{1} & \multirow{5}{*}{$-0.0039 \pm j 0.0559$} & \multirow{5}{*}{0.0695} & 3.0024 \\
\hline & & & 0.8891 \\
\hline & & & 1.1228 \\
\hline & & & 4.7844 \\
\hline & & & 2.6112 \\
\hline \multirow{5}{*}{2} & \multirow{5}{*}{$-0.0023 \pm j 0.0370$} & \multirow{5}{*}{0.0621} & 3.0151 \\
\hline & & & 0.8582 \\
\hline & & & 1.1318 \\
\hline & & & 4.7838 \\
\hline & & & 2.5696 \\
\hline
\end{tabular}

Table 9. Ranking-Critical swing modes (SOES).

\begin{tabular}{cccccc}
\hline Rank & $\begin{array}{c}\text { Critical } \\
\text { mode }\end{array}$ & Critical mode & $\begin{array}{c}\text { Damping } \\
\text { ratio }\end{array}$ & $\begin{array}{c}\text { Operating } \\
\text { condition }\end{array}$ & $\begin{array}{c}\text { Machine } \\
\text { No. }\end{array}$ \\
\hline 1 & Mode 1 & $-0.0031 \pm 0.0593 \mathrm{i}$ & 0.0527 & (b) & 4 \\
2 & Mode 2 & $-0.0005 \pm 0.0385 \mathrm{i}$ & 0.0128 & (a) & 2 \\
\hline
\end{tabular}

Table 10. Tuned parameters of PSS.

\begin{tabular}{ccccccc}
\hline \multirow{2}{*}{$\begin{array}{c}\text { Machine } \\
\text { No. }\end{array}$} & \multicolumn{2}{c}{$\begin{array}{c}\text { Operating } \\
\text { condition (a) }\end{array}$} & \multicolumn{2}{c}{$\begin{array}{c}\text { Operating } \\
\text { condition (b) }\end{array}$} & \multicolumn{2}{c}{$\begin{array}{c}\text { Operating } \\
\text { condition (c) }\end{array}$} \\
\cline { 2 - 7 } & $\boldsymbol{K}_{\text {pss }}$ & $\boldsymbol{T}_{1}$ & $\boldsymbol{K}_{\text {pss }}$ & $\boldsymbol{T}_{1}$ & $\boldsymbol{K}_{\text {pss }}$ & $\boldsymbol{T}_{1}$ \\
\hline 1 & 76.0 & 0.0127 & 62.3 & 0.0135 & 77.9 & 0.0130 \\
2 & 45.0 & 0.1200 & 39 & 0.0123 & 49.6 & 0.0123 \\
3 & 53.3 & 0.0329 & 54.6 & 0.0990 & 35.3 & 0.0971 \\
4 & 54.7 & 0.0125 & 45 & 0.0128 & 55.3 & 0.0126 \\
$\mathbf{5}$ & 29.0 & 0.0732 & 23.9 & 0.0936 & 21.2 & 0.0926 \\
\hline
\end{tabular}




\section{Simulation Results}

The application of the FOES and SOES is demonstrated by applying it to the five-machine, eight bus system. The time domain simulations of rotor angle deviation of the system are carried out without PSS and with PSSs located on machines $2 \& 4$ after tuning the PSS parameters. The corresponding system response of initial perturbation of $5^{\circ}$ in rotor angle at machine 2, 3, 4 and 5 with respect to machine 1 for operating condition 1) and 2) are shown in Figures 3(a)-(d) to 4(a)-(d) respectively.

Similar type of responses was occurring for the operating condition 3) also. The effectiveness of the first and second order eigenvalue sensitivities methods is compared with the participation factor method in selecting the optimum location for placement of PSSs [16]. Figures 5(a)-(c) are the comparison of the system responses for operating conditions 1 ), 2) and 3 ) under $5^{\circ}$ rotor angle perturbation.

\section{Conclusions}

In this paper, an eigen-sensitivity of the system matrix is

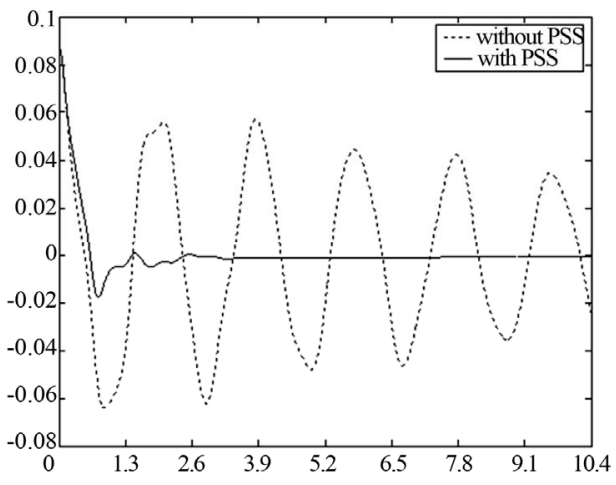

(a)

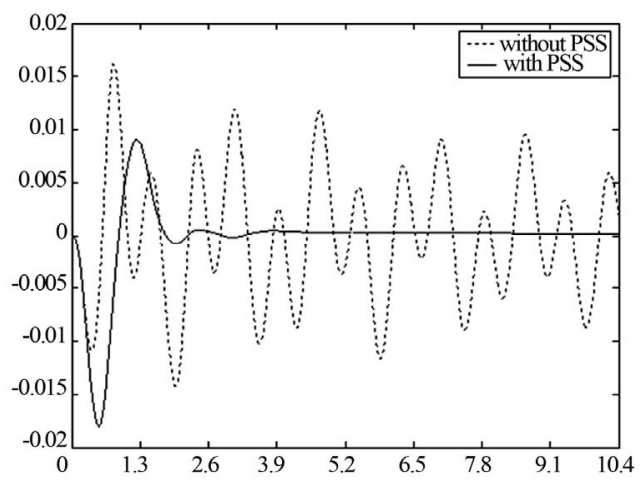

(c) developed using a dominant eigenvalue and the corresponding eigenvectors. The proposed sensitivity can provide valuable information in enhancing power system stability identifying the siting of compensation device PSS. The results of the method indicate that machines 2 and 4 are the optimum locations for installing PSSs.

The eigenvalue sensitivity analysis is used to find out optimum location of PSS for different operating conditions and gives the best damping of all the critical modes of the system. The work in this paper is concerned with the location Power system stabilizers in multimachine power systems and tuning its parameters. This work has got great practical relevance for the modern power systems, where the ever increasing demand for the electrical power and the integration of large utilities have been regularly causing the system to operate at the threshold of its stability limits, which calls for adequate precautionary measures to be taken to ensure rotor angle stability of the synchronous machines. An efficient computer-programming package for analyzing the dynamic stability of power systems has been developed in MATLAB. Using the first and second order sensitivity the

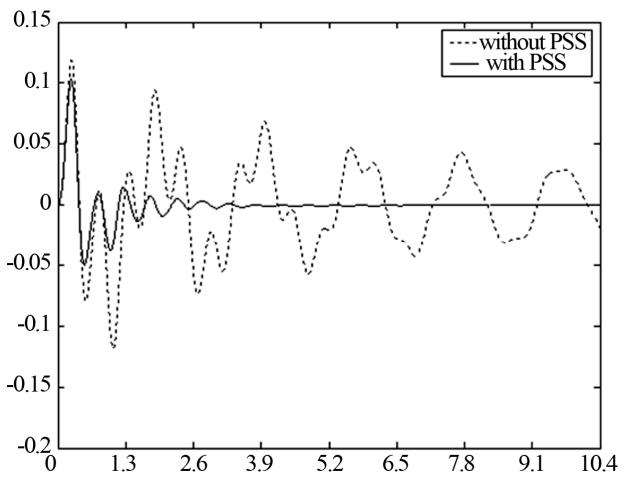

(b)

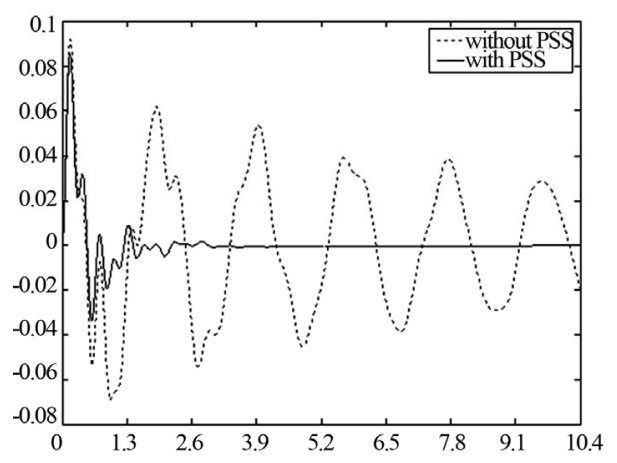

(d)

Figure 3. (a) System response of $\Delta \delta_{12}$-op.condition (a) with an initial perturbation of $5^{\circ}$; (b) System response of $\Delta \delta_{13}$-op.condition (a) with an initial perturbation of $5^{\circ}$; (c) System Response of $\Delta \delta_{14}$-op.condition (a) with an initial perturbation of $5^{\circ}$; (d) System response of $\Delta \delta_{15}$-op.condition (a) with an initial perturbation of $5^{\circ}$. 


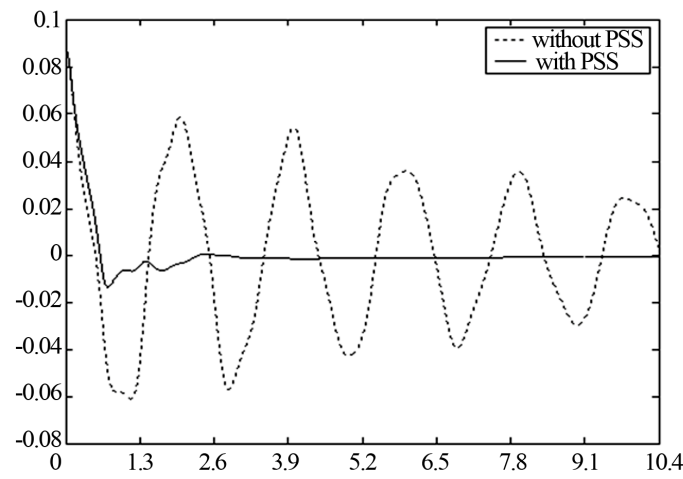

(a)

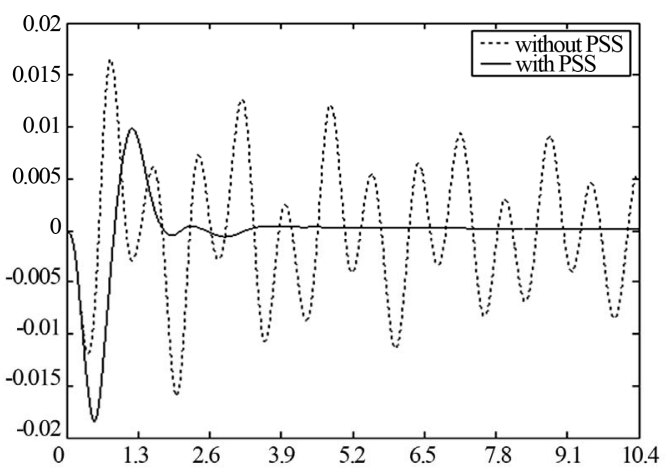

(c)

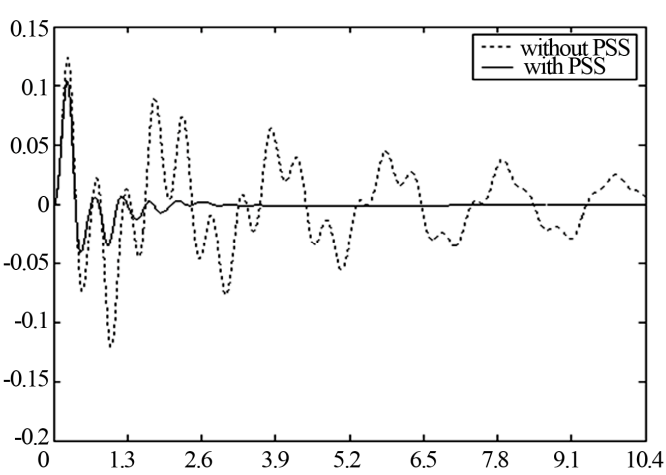

(b)

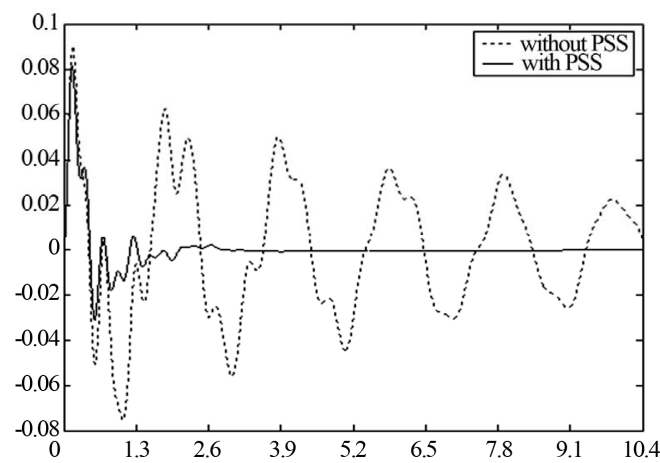

(d)

Figure 4. (a) System response of $\Delta \delta_{12}$-op.condition (b) with an initial perturbation of $5^{\circ}$; (b) System response of $\Delta \delta_{13}$-op.condition (b) with an initial perturbation of $5^{\circ}$; (c) System Response of $\Delta \delta_{14}$-op.condition (b) with an initial perturbation of $5^{\circ}$; (d) System response of $\Delta \delta_{15}$-op.condition (b) with an initial perturbation of $5^{\circ}$.

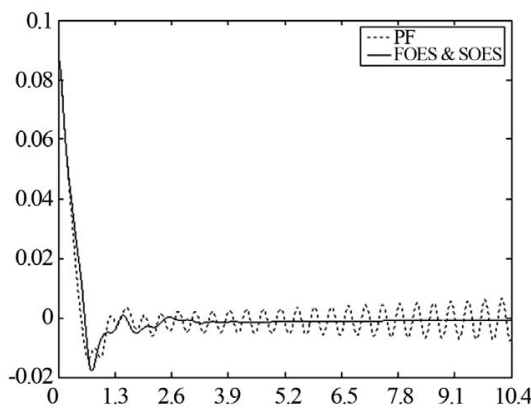

(a)

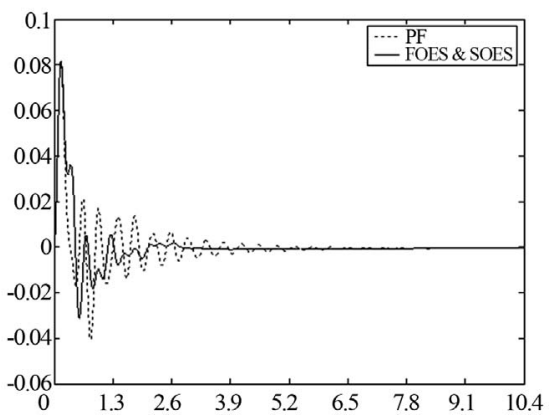

(b)

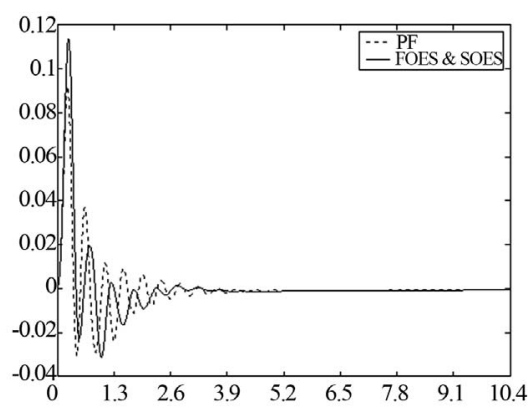

(c)

Figure 5. (a) System Response of $\Delta \delta_{12}$-op.condition (a) with an initial perturbation of $5^{\circ}$; (b) System Response of $\Delta \delta_{15}$ op.condition (b) with an initial perturbation of $5^{\circ}$; (c) System Response of $\Delta \delta_{13}$-op.condition (c) with an initial perturbation of $5^{\circ}$.

machines creating the critical swing modes are identified, which can be proposed as the optimum locations for placing the power system stabilizers.

\section{REFERENCES}

[1] P. Lakshmi and M. A. Khan, "Design of a Robust Power System Stabilizer Using Fuzzy Logic for a Multi-Ma- chine Power System," International Journal on Electric Power Systems Research, Vol. 47, No. 4, 1998, pp. 39-46.

[2] E. Z. Zhout, O. P. Malik and G. S. Hope, "Theory and Method for Selection of Power System Stabilizer Location," IEEE Transactions on Energy Conversion, Vol. 6, No. 1, 1991, pp. 170-176. doi:10.1109/60.73804

[3] De Mello, et al., "Coordinated Application of Stabilizers in Multi-Machine Power Systems," IEEE Transactions on 
Power Apparatus and Systems, Vol. PAS-99, No. 3, 1980, pp. 227-230.

[4] T. Hiyama, "Coherency Based Identification of Optimum Site for Stabilizer Applications," IEE Proceedings C on Generation, Transmission and Distribution, Vol. 130, No. 2, 1983, pp. 71-74.

[5] P. Zhang and A. H. Coonick, "Coordinated Synthesis of PSS Parameters in Multi-Machine Power Systems Using the Method of Inequalities Applied to Genetic Algorithms," IEEE Transactions on Power Systems, Vol. 15, No. 3, 2000, pp. 811-816. doi:10.1109/59.867178

[6] A. L. B. Do Bomfim, G. N. Taranto and D. M. Falcao, "Simultaneous Tuning of Power System Damping Controllers Using Genetic Algorithms," IEEE Transactions on Power Systems, Vol. 15, No. 1, 2000, pp. 163-169. doi:10.1109/59.852116

[7] L. J. Cai and L. Elrich, "Simultaneous Coordinated Tuning of PSS and FACTS Controller for Damping Power System Oscillations in Multi-Machine Systems," 2003 IEEE Bologna Power Tech Conference Proceedings, Vol. 2, 23-26 June 2003, pp. 1025-1030.

[8] A. Doi and A. Abe, "Coordinated Synthesis of Power System Stabilizers in a Multi-Machine Power System," IEEE Transactions on Power Apparatus and Systems, Vol. 103, No. 6, 1984, pp. 1473-1479. doi:10.1109/TPAS.1984.318486

[9] H.-K. Nam, Y.-K. Kim, K.-S. Shim and K. Y. Lee, "A New Eigen-Sensitivity Theory of Augmented Matrix \& Its Applications to Power System Stability Analysis,"
IEEE Transactions on Power Systems, Vol. 15, No. 1, 2000, pp. 363-369. doi:10.1109/59.852145

[10] P. Kundur, "Power System Stability and Control," McGraw Hill Inc., New York, 1994.

[11] H. M. Zein El-Din and R. T. H. Alden, "Second Order Eigenvalue Sensitivites Applied to Power System Dynamics," IEEE Transactions on Power Apparatus and Systems, Vol. PAS-96, No. 6, 1977, pp. 1928-1936. doi:10.1109/T-PAS.1977.32528

[12] J. V. Milanovie, "Identification of Electromechanical Modes and Placement of PSSs Using Relative Gain Array," IEEE Transactions on Power Systems, Vol. 19, No. 1, 2004, pp. 410-417. doi:10.1109/TPWRS.2003.821454

[13] P. M. Anderson and A. A. Fouad, "Power System Control and Stability," Iowa State University Press, Iowa, 1997.

[14] C. Y. Chung, K. W. Wang, C. T. Tse, X. Y. Bian and A. K. David, "Probabilistic Eigenvalue Sensitivity Analysis and PSS Design in Multimachine Systems," IEEE Transactions on Power Systems, Vol. 18, No. 4, 2003, pp. 1439-1445. doi:10.1109/TPWRS.2003.818709

[15] C. Y. Chung, K. W. Wang, C. T. Tse and R. Niu, "Power System Stabilizer Design by Probabilistic Sensitivity Indexes," IEEE Transactions on Power Systems, Vol. 17, No. 3, 2002, pp. 688-693. doi:10.1109/TPWRS.2002.800914

[16] Y. Y. H Su and C. L. Chen, "Identification of Optimum Location for Stabilizer Applications Using Participation Factors," IEE Proceedings, Vol. 134, No. 3, 1987, pp. 237-245. 